\title{
Serum progesterone in first trimester of normal pregnancy
}

\author{
Sathya Selvarajan ${ }^{1}$, Jothimalar $\mathbf{R}^{2, *}$ \\ ${ }^{1}$ Research Scholar, ${ }^{2}$ Professor, Dept. of Biochemistry, Sri Ramachandra Medical College \& Research Institute, Chennai, \\ Tamil Nadu, India
}

*Corresponding Author: Jothimalar R

Email: drjothimalar@gmail.com

Received: $22^{\text {nd }}$ June, 2018

Accepted: $21^{\text {st }}$ July, 2018

\section{Introduction}

Progesterone $(\mathrm{P})$ is secreted by the corpus luteum during the luteal phase of menstrual cycle to prime the endometrium for implantation of the blastocyst. On implantation of a fertilized embryo, the corpus luteum continues to produce $\mathrm{P}$ until the placenta takes over majority of this function, which is around 10 weeks of gestation.

Maternal P guarantees proper growth of the endometrium, sufficient vascularization of the uterus, tissue repair, regeneration and preparation of the uterus for labor. ${ }^{1}$ Studying the levels of P from 4 to 10 weeks of gestation can be used to identify a normal corpus luteum which probably indicates a normal pregnancy. However, due to limited clinical validation of the marker, it is not being used routinely to identify any abnormalities at an early stage of pregnancy. ${ }^{2,3}$ If the pregnancy progresses beyond 10 weeks of gestation, ultrasound imaging can easily identify conditions like ectopic and failed pregnancies. The aim of this study was to identify the levels of $\mathrm{P}$ in women with a normal pregnancy in the early period of $4-10$ weeks in their first trimester.

\section{Materials and Methods}

This observational cross sectional study was performed at Sri Ramachandra Medical College Hospital \& Research Institute (SRMC \& RI), Chennai, Tamil Nadu. All procedures performed in this study were in accordance with the ethical standards of the Institutional Ethics Committee and with the 1964 Helsinki declaration and its later amendments or comparable ethical standards. Informed consent was obtained from all individual participants included in the study.

The study group comprised of 140 women in the age group of $19-42$ years. 140 pregnant women between $4-10$ weeks of gestation presenting for their booking visit to the OBG department were chosen sequentially. Only women who fulfilled the following conditions were included: 1) Females aged 18 years and above, 2) Serum $\beta$ hCG $\geq 5$ IU/L, 3) Singleton normal gestation confirmed by ultrasonography and 4) Gestational age $\leq 10$ weeks. Maternal age and gravidity of all subjects participating in the study were documented. Their ultrasound reports were used to identify the gestational age. Venous blood was drawn by a trained phlebotomist from these women and collected in serum separator tubes. Serum was separated and $\mathrm{P}$ was quantified by Direct Chemiluminescence on the Beckman Coulter Unicel Dxl 800 Immunoassay platform (Beckman Coulter Life Sciences, Indianapolis, IL, USA). Statistical analyses was performed using Statistical Package for the Social Sciences software for Windows, version 16.0 (SPSS Inc., Chicago, IL, USA), and a p value less than 0.05 was considered statistically significant.

\section{Results}

The baseline characteristics of the study population and mean values of $\mathrm{P}$ are tabulated in Table 1 . The average maternal age was $24.8 \pm 3.5$ years and mean gestational age was $6.3 \pm 1.6$ weeks. The mean gravidity was $1.4 \pm 0.5$; 93 of the 140 women were primi-gravidas which accounted for $66.4 \%$ of the total and the remaining $47(33.6 \%)$ were multigravidas with either a second or third pregnancy. The mean concentration of $\mathrm{P}$ was found to be $24.6 \pm 8.8$ (range $=$ $10.32-53.54) \mathrm{ng} / \mathrm{ml}$.

Gestational week wise mean, SD and range were calculated. Correlation of gestational age with $\mathrm{P}$ values was performed by determining Karl Pearson's correlation coefficient (Table 2). The $r$ value for week wise correlation was 0.868 and was statistically significant at $\mathrm{p} 0.000$.

A scatter plot demonstrating the distribution of $\mathrm{P}$ values across gestational age is shown in Fig. 1. A gradational increase in $\mathrm{P}$ values along with the progression of pregnancy is noted.

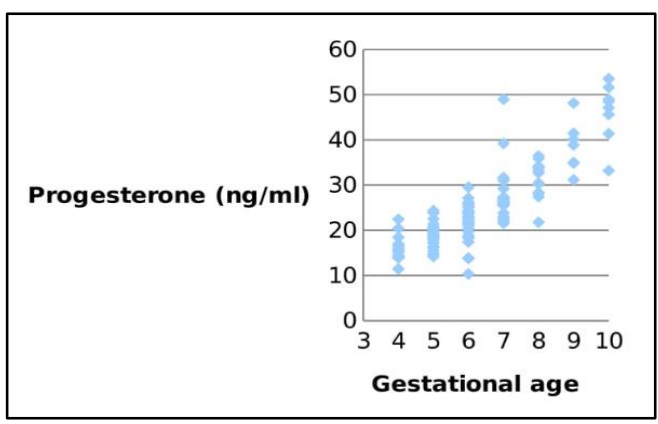

Fig. 1: Scatter plot for Progesterone values based on gestational age 
Table 1: Characteristics of study population

\begin{tabular}{|l|c|c|}
\hline \multicolumn{1}{|c|}{ Variable } & Mean \pm SD & Range \\
\hline Maternal age(years) & $24.8 \pm 3.5$ & $19-42$ \\
\hline Gestational age (weeks) & $6.3 \pm 1.6$ & $4-10$ \\
\hline Gravidity & $1.4 \pm 0.5$ & $1-3$ \\
\hline Progesterone (ng/ml) & $24.6 \pm 8.8$ & $10.32-53.54$ \\
\hline
\end{tabular}

Table 2: Correlation of gestational age with Progesterone (ng/ml) values

\begin{tabular}{|c|c|c|c|c|c|}
\hline $\begin{array}{l}\text { Gestational } \\
\text { age(weeks) }\end{array}$ & $\mathbf{N}$ of cases & $\begin{array}{c}\text { Progesterone } \\
\text { Mean (SD) }\end{array}$ & Minimum & Maximum & r value \\
\hline 4 & 15 & $16.0(2.8)$ & 11.5 & 22.4 & \multirow[t]{4}{*}{0.868} \\
\hline 5 & 34 & $18.8(2.6)$ & 14.2 & 24.4 & \\
\hline 6 & 38 & $21.9(3.8)$ & 10.3 & 29.5 & \\
\hline 7 & 25 & $27.6(5.8)$ & 21.6 & 49.0 & \\
\hline 8 & 13 & $31.3(4.1)$ & 21.8 & 36.5 & \multirow{3}{*}{$\begin{array}{c}\mathrm{p} \text { value } \\
0.000\end{array}$} \\
\hline 9 & 7 & $38.5(5.5)$ & 31.2 & 48.1 & \\
\hline 10 & 8 & $46.2(6.4)$ & 33.2 & 535 & \\
\hline
\end{tabular}

\section{Discussion}

Progesterone is pregn4-ene, 3, 20-dione, a 21 carbon structured molecule that contains a keto group at the $3^{\text {rd }}$ carbon and a double bond linking the $4^{\text {th }}$ and $5^{\text {th }}$ carbons, both of which are important for its biological role in the preparation of the uterus for implantation of the fertilized embryo. ${ }^{4} \mathrm{P}$ has been explored as a diagnostic biomarker of pregnancy in various research studies. ${ }^{5-8}$ However, gestational age specific reference ranges for $\mathrm{P}$ have not been established so far in most studies. The reason being that in most cases gestational age was either not known or not reported in these studies. In the current study only the subjects who underwent an ultrasound assessment were included, and their gestational age was documented.

The average maternal age was $24.9 \pm 3.5$ years and mean gestational age was $6.3 \pm 1.6$ weeks. 93 of the 140 women were primi-gravidas which accounted for $66.4 \%$ of the total and the remaining $47(33.6 \%)$ were multigravidas with either a second or third pregnancy. The mean concentration of Progesterone was found to be $24.6 \pm 8.8$ (range $=10.32-53.54) \mathrm{ng} / \mathrm{ml}$. On dividing the subjects, based on gestational age, a difference was observed in their P levels but gestational age specific reference intervals could not be calculated as the number of samples in each sub-group was less for statistical analysis.

A statistically significant gradational increase was noticed in the $\mathrm{P}$ levels as pregnancy advanced. The $\mathrm{r}$ value for week wise correlation was 0.868 and was statistically significant at p 0.000 . Nevertheless, in a meta-analysis by Mol et al which included 26 research papers between 1966 and 1988, serum P levels were found to vary, very minimally between 5 to 10 weeks of gestation and so they assumed that the increase or decrease in the gestational age will not have any bearing on the hormone's levels. ${ }^{9}$ Similar findings were reported in studies conducted by Ibrahim et $\mathrm{al}^{2}$ and Zainab et al. ${ }^{3}$
However in the same meta-analyses by Mol et al, the authors say that in studies by Lower et al and Stern et al, the capability of serum $\mathrm{P}$ to distinguish a normal pregnancy from failing pregnancies, increases as the gestational age increases. ${ }^{9}$ Further analysis by increasing the number of subjects in each gestational age is necessary to establish gestational age specific reference intervals for this vital hormone.

\section{Conclusion}

There is a gradual increase in the $\mathrm{P}$ concentration as the gestational age increases. There is a statistically significant positive correlation between the level of $\mathrm{P}$ and the gestational age of the women.

\section{Clinical Significance}

Levels of $\mathrm{P}$ in early pregnancy aid in determining the adequacy of corpus luteal functioning, and in discerning a normal pregnancy from a non-viable pregnancy. Establishing a gestational age specific reference interval for this hormone can assist in the same.

\section{Acknowledgement}

The authors convey their thankfulness to the Indian Council of Medical Research (ICMR), New Delhi for providing financial aid as TSS fellowship: $\mathrm{PhD}$ (Integrated)-30-F.T./I/2014. The authors deny any conflicts of interest in relation to this study.

\section{References}

1. Arck P, Hansen PJ, Mulac Jericevic B, Piccinni M-P, Szekeres-Bartho J. Progesterone during pregnancy: endocrine-immune cross talk in mammalian species and the role of stress. Am J Reprod Immunol. 2007;58(3):268-79.

2. Ibrahim A, Maha M, Hanan H. Relation between single serum progesterone assay and viability of the first trimester pregnancy. Asian Pac J Reprod. 2013;2:34-37. 
3. Jufairi Zainab Ali Abdulla Al. The value of serum progesterone measurement in early pregnancy. Bahrain Med Bull. 2000;22(1).

4. Rifai N, Horvath AR, Wittwer C. Tietz textbook of clinical chemistry and molecular diagnostics (Sixth edition). 2018. St. Louis, Missouri: Elsevier.

5. Hanita O, Hanisah AH. Potential use of single measurement of serum progesterone in detecting early pregnancy failure. Malaysian Journal of Pathology. 2012;34(1):41-46.

6. Hahlin M, Sjöblom P, Lindblom B. Combined use of progesterone and human chorionic gonadotropin determinations for differential diagnosis of very early pregnancy. Fertil Steril. 1991;55(3):492-496.

7. al-Sebai MA, Kingsland CR, Diver M, Hipkin L, McFadyen IR. The role of a single progesterone measurement in the diagnosis of early pregnancy failure and the prognosis of fetal viability. Br J Obstet Gynaecol. 2005;122:364-9.
8. Daily CA, Laurent SL, Nunley WC., Jr The prognostic value of serum progesterone and quantitative beta-human chorionic gonadotropin in early human pregnancy. Am J Obstet Gynecol. 1994;171:380-4.

9. Mol BW, Lijmer JG, Ankum WM, van der Veen F \& Bossuyt PM. The accuracy of single serum progesterone measurement in the diagnosis of ectopic pregnancy: a meta-analysis. Human Reproduction. 1998;13(11):32203227.

How to cite this article: Selvarajan $S$, Jothimalar R. Serum progesterone in first trimester of normal pregnancy. Int $\mathrm{J}$ Clin Biochem Res. 2018;5(4):651-653. 